\title{
Scleroderma and HIV Infection: A Case Report with Literature Review
}

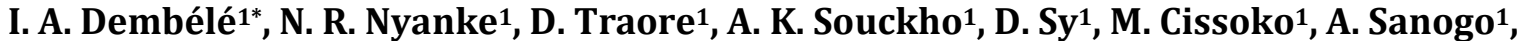

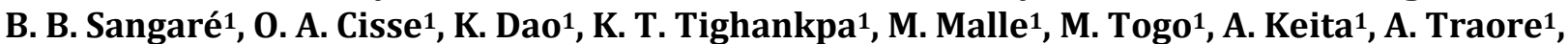

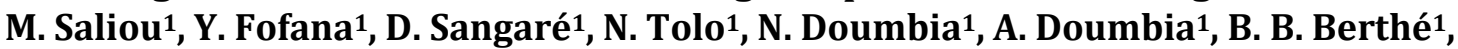 \\ B. D. Camara' ${ }^{1}$, S. A. Coulibaly ${ }^{1}$, N. Sawadogo ${ }^{2}$, M. Dembélé1, A. K. Traore ${ }^{1}$, H. A. Traore ${ }^{1}$
}

${ }^{1}$ Internal Medicine Department, Point G Teaching Hospital, Bamako, Mali

${ }^{2}$ Department of Internal Medicine, Kaya Regional Hospital, Kaya, Burkina Faso

Email: ^ibadem1@yahoo.fr

How to cite this paper: Dembélé, I.A., Nyanke, N.R., Traore, D., Souckho, A.K., Sy, D., Cissoko, M., Sanogo, A., Sangaré, B.B., Cisse, O.A., Dao, K., Tighankpa, K.T., Malle, M., Togo, M., Keita, A., Traore, A., Saliou, M., Fofana, Y., Sangaré, D., Tolo, N., Doumbia, N., Doumbia, A., Berthé, B.B., Camara, B.D., Coulibaly, S.A., Sawadogo, N., Dembélé, M., Traore, A.K. and Traore, H.A. (2018) Scleroderma and HIV Infection: A Case Report with Literature Review. Open Journal of Internal Medicine, 8, 255-260.

https://doi.org/10.4236/ojim.2018.84024

Received: July 25, 2018

Accepted: December 26, 2018

Published: December 29, 2018

Copyright ( 92018 by authors and Scientific Research Publishing Inc. This work is licensed under the Creative Commons Attribution International License (CC BY 4.0). http://creativecommons.org/licenses/by/4.0/

Open Access

\begin{abstract}
Introduction: Acquired immunodeficiency syndrome (AIDS) linked to HIV infection is accompanied by auto-immune phenomena. Autoimmune diseases can develop in people living with HIV, most in a context of good immunological control (vasculitis, anti-phospholipid syndrome). Since the advent of antiretroviral therapy, an increasing number of autoimmune connective tissue diseases such as systemic lupus erythematosus, dermatomyositis, and syndromes of Sjögren and scleroderma have been reported. Purpose: To describe this association's not very common scleroderma and HIV infection. Observation: We report the case of a 56-year-old lady admitted into the service for functional impotence that would have been evolving for a week. Prior to her hospitalization, she presented edemas of the lower limbs associated with anesthesia of the lower limbs for 5 months. The painting is accompanied by a productive cough and an intermittent fever. At the physical examination a weight loss $\left(\mathrm{BMI}=13.74 \mathrm{Kg} / \mathrm{m}^{2}\right)$, fever $\left(38.7^{\circ} \mathrm{C}\right)$ : Oral candidiasis, lower lip ulceration, perlicking, undernutrition folds, sclerodactyly and homogeneous hepatomegaly was noted. The diagnosis of immunosuppression to HIV Stage 3 with TB co-morbidity and positive hepatitis B Serology was retained while diffuse Scleroderma was selected from the ACR/EULAR criteria of 2012 with a score of 10 (sclerodactyly $=4$ point; Raynaud's phenomenon $=3$ point and Ac Anti Scl 70 positive $=3$ point). Conclusion: These associations of chronic pathology must be described to improve the future treatment of our patients.
\end{abstract}

\section{Keywords}

Scleroderma, HIV, Internal Medicine 


\section{Introduction}

The occurrence of autoimmune diseases (MAI) implies the presence in the peripheral directory of self-reactive lymphocyte clones whose activation and differentiation are induced and guided by Autoantigens. The MAI are, for the most part, multifactorial diseases. They involve genetic factors, environmental factors and stochastic factors that converge to put into action or regulate the main pathways of functioning of innate and adaptive immune systems [1]. The acquired immunodeficiency syndrome (AIDS) linked to HIV infection is also accompanied by autoimmune phenomena. Autoimmune diseases can develop in people living with HIV (PHAs), most in a context of good immunological control. Some of these may allow the diagnosis of HIV infection at a moderate stage of immune deficiency (vasculitis, anti-phospholipid syndrome) [2]. Since the advent of antiretroviral therapy (ART), an increasing number of autoimmune connective tissue diseases such as systemic lupus erythematosus (LES), Dermatomyositis, syndromes of Sjögren and scleroderma have been reported most often with an immune restoration syndrome. Scleroderma is an autoimmune disorder manifested by inflammation and fibrosis of various organs. It can predominantly affect the skin with or without participation of other organs (localized scleroderma) or may manifest itself both through cutaneous involvement and internal organs of the organism (diffuse scleroderma). Only a few cases on the spectrum of the relationship with HIV are reported in the literature [3].

We report the case of a 56-year-old woman whose diagnoses of HIV infection and diffuse scleroderma were made concomitantly with a viral co to hepatitis B.

\section{Observation}

Ms. F.K. 56 years admitted to the service for functional impotence and edema of the lower bilateral limbs. Impotence would have occurred one week prior to hospitalization associated with urinary incontinence. This would be preceded by more than 5 months of edema of the white lower limbs with anesthesia of the soles of the feet and paresthesia to type of cramp occurring intermittently, a persistent fever, a productive cough with sputum hémoptoïques. The patient also reported a succession of white fingers with anesthesia followed by paresthesia to the type of needle in the fingers and painful, red and swollen fingers (Raynaud's phenomenon). The patient had presented a chickenpox 4 weeks before her hospitalization and then 2 weeks later a shingle. A emaciated patient was noted for physical examination with a body mass index of $13.74 \mathrm{Kg} / \mathrm{m}^{2}$, a temperature of $38.7^{\circ} \mathrm{C}$, oral candidiasis, an ulceration of the lower lip, a perlicker, creases in malnutrition, a sclerodactyly with the sign of the Present Prayer (Figure 1), a homogeneous hepatomegaly with foam bottom edge, pulmonary condensation syndrome, anxiety, painful and arthrokinétique sensitivity disorders, muscle strength rated at 0/5 to lower limbs, a sphincter hypotonia, Osteo-tendon reflexes were abolished at the lower limbs.

The results of the biological assessment are shown in the table below (Table 1) 
Chest X-ray objective was a bilateral pneumonia with minimal right pleurisy. In addition, an abdominal ultrasound noted a homogeneous hepatosplenomegaly without focal lesion; an Oeso-gastroduodenal fibroscopy showed a erythematous antrite without signs of portal hypertension. Dorso radiography found a dorsolombarthrose. The Dorso Lumbar CT has not been done or the skin biopsy.

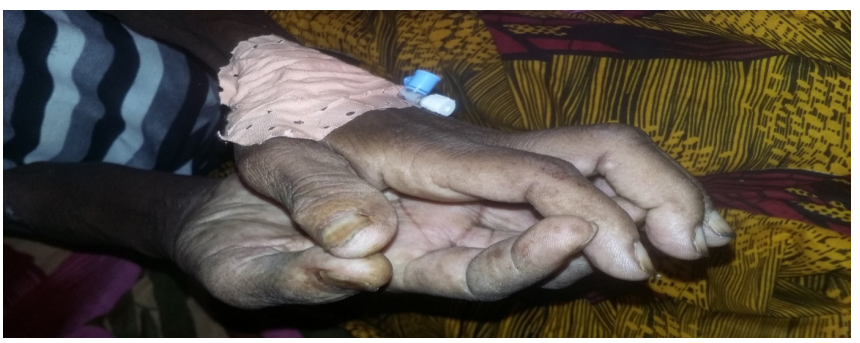

Figure 1. Image showing a sclerodactyly of both hands.

Table 1. Results of biological assessment.

\begin{tabular}{|c|c|}
\hline Biology report & Results \\
\hline HIV Serology Type 1 & Positive \\
\hline $\mathrm{CD} 4$ & $102 \mathrm{cel} / \mu \mathrm{l}$ \\
\hline HIV viral load & $3,222,717$ copies $/ \mathrm{ml}$ \\
\hline Hemoglobin & $5.99 \mathrm{~g} / \mathrm{dl}$ \\
\hline Ferritin & $1102.44 \mathrm{ng} / \mathrm{ml}$ \\
\hline Albumin & $24 \mathrm{~g} / \mathrm{l}$ \\
\hline \multicolumn{2}{|l|}{ Prothrombin } \\
\hline ASAT & $87 \mathrm{U} / 1$ \\
\hline ALAT & $30 \mathrm{U} / 1$ \\
\hline creatinine & $55 \mu \mathrm{mol} / 1$ \\
\hline urea & $4.42 \mathrm{mmo} / \mathrm{l}$ \\
\hline HBsantigen & Positive \\
\hline Anti HBcIgG Antibody & Positive \\
\hline Anti HCV Antibody & Negative \\
\hline Tick drop & Negative \\
\hline Search for acid-fast bacilli & Negative \\
\hline Cytobacterioligical urine exam & Presence of Escherichia coli \\
\hline Anti-nuclear antibodies & Positive (1.78 UE) \\
\hline Anti Scl 70 antibody & Positive (28.96 UE) \\
\hline Native anti DNA antibodies & Negative \\
\hline Anti Smantibodies & Negative \\
\hline Cephalinphospho kinase (CPK) & $23 \mathrm{UI} / \mathrm{L}$ \\
\hline
\end{tabular}


Diagnoses in the patient based on clinical and paraclinical arguments were: who immunosuppression to HIV Stage 3, urinary infection with Escherichia coli, erythematous antrite, chronic hepatitis $\mathrm{B}$, and Diffuse scleroderma deducted from the criteria of ACR/EULAR (American College of Rheumatology (ACR), in partnership with the European League against Rheumatism (EULAR)) of 2012 with a score of 10 point (sclerodactyly $=4$ point; Raynaud's phenomenon $=3$ Point and Ac Anti Scl 70 positive = 3 point) in the patient. It was treated with tenofovir 300 + lamivudine 300 + Effavirenz 600: 1 comp/day for HIV infection and HBV; Amitryptilline for Neuropathies; Fluconazole $150 \mathrm{mg} 1 \mathrm{gel} /$ day for candidiasis; Treatment of urinary tract infection was nitofurantoïne $50 \mathrm{mg} 1$ Comp 3 times/day. For scleroderma the patient was treated with Prednisone 20 $\mathrm{mg}$ due to $1 \mathrm{mg} / \mathrm{kg} /$ day and as a background treatment of synthetic antimalarial drugs.

The evolution was favorable with an exit in post hospitalization 10 days after the start of treatment. It remains in regular follow-up for these chronic pathologies.

\section{Discussion}

The Immunosuppression association with HIV and Scleroderma is seldom reported. In fact, the literature review finds only 3 studies that describe 4 cases of scleroderma associated with HIV. Several cohort studies of HIV-infected patients sought association with autoimmune diseases, but only 2 of them found this association: The first one doing a review of the literature of rheumatologic events associated with HIV type I involving 888 patients finds a case of scleroderma [4]; The second was to determine the incidence of autoimmune diseases in PHAs in TAIWAN, with 20,444 patients finding 4 cases of this association [5].

Only the case described by Sikdar et al., in 2005 referred to the diagnosis of scleroderma and HIV infection at the same time [6]. For all others, the diagnosis of scleroderma occurred after some time of evolution of the immunosuppression and/or the treatment of ARV [3] [5] [7] probably related to immune restoration syndrome. Autoimmune and systemic diseases have been described in HIV-infected patients and a classification by immune status has been proposed. During stage I, it is the acute infection with HIV and the immune system is intact. At this stage, autoimmune diseases may be present. While stage II is a period of rest without manifestations of HIV infection, there is a decrease in the number of CD4 $\mathrm{T}$ lymphocyte indicative of a certain immunosuppression. In stage III, there is immunosuppression with a small number of CD4 T lymphocyte. However, diseases where the cell T subtype CD8 predominant as psoriasis and diffuse immune lymphocytic syndrome (similar to Sjogren syndrome) may be present or even be the initial manifestation of AIDS. At stage IV, there is a restoration of immune competence after antiretroviral therapy. In this context, there may be a resurgence of autoimmune diseases [8].

The case of this 56-year-old patient diagnosed with scleroderma and HIV in- 
fection was concomitantly and was also not receiving treatment (which could have stimulated an immune restoration) and had a CD4 $=102$-cell ratio with $\mathrm{CD} 4 / \mathrm{CD} 8=0.17$ suggests several hypotheses. As proposed by Zandmann-Goddard et al. [8], this patient is in stage III and should not have autoimmune diseases, so would the deficit in the T-cell scale be the pathophysiological mechanism of scleroderma occurrence? Unlike other studies where the diagnosis was made after a period of evolution of HIV infection and/or after art, Could HIV be responsible for the existence of Scleroderma as assumed by Sikdar et al. [6], which described a case of simultaneous diagnosis?

The patient also has a hepatitis B infection that is often implicated in the occurrence of autoimmune diseases. Diallo andcol [9] reported a case of scleroderma associated with secondary Sjögren's syndrome in their series. In this case, the role of HIV, hepatitis B or both antigens in the development of scleroderma remains uncertain. In spite of the poor knowledge of the pathogenesis of autoimmune diseases associated with HIV infection and viral infections in the short term, we can say that there is a link between HIV infection and the incidence of autoimmune diseases as shown by Yen et al. [5].

\section{Conclusion}

The issues raised by this observation further underline the lack of knowledge and understanding about the HIV and Scleroderma Association and even the association of HIV and Autoimmune diseases. This could allow new therapeutic pathways.

\section{Conflicts of Interest}

The authors declare no conflicts of interest regarding the publication of this paper.

\section{Consent}

The patient's informed consent was obtained.

\section{References}

[1] Tron, F. and Bach, J.F. (2015) Concepts actuels de l'auto-immunité. In: Guillevin, L., Meyer, O., Hachulla, E. and Sibilia, J., Eds., Traité des maladies et syndromes systémiques, 6e edition, Lavoisier, Paris, 105-123.

[2] Iordache, L., Launay, O., Bouchaud, O., Jeantils, V., Goujard, C., Boue, F., et al. (2014) Autoimmune Diseases in HIV-Infected Patients: 52 Cases and Literature Review. Autoimmunity Reviews, 13, 850-857. https://doi.org/10.1016/j.autrev.2014.04.005

[3] Okong'o, L.O., Webb, K. and Scott, C. (2015) HIV-Associated Juvenile Systemic Sclerosis: A Case Report. Seminars in Arthritis and Rheumatism, 44, 411-416. https://doi.org/10.1016/j.semarthrit.2014.08.005

[4] Yao, Q., Frank, M., Glynn, M. and Altman, R.D. (2008) Rheumatic Manifestations in HIV-1 Infected In-Patients and Literature Review. Clinical and Experimental Rheumatology, 26, 799-806. 
[5] Yen, Y.-F., Chuang, P.H., Jen, I.-A., Chen, M., Lan, Y.-C., Liu, Y.-L., et al. (2016) Incidence of Autoimmune Diseases in a Nationwide HIV/AIDS Patient Cohort in Taiwan, 2000-2012. Annals of the Rheumatic Diseases, 76, 1-5

[6] Sikdar, S., Grover, C., Kubba, S., Yadav, A., Sahni, V., Aggarwal, G., et al. (2005) An Uncommon Cause of Scleroderma. Scandinavian Journal of Rheumatology, 34, $242 \mathrm{e} 5$.

[7] Mosquera, J.A., Ojea, R. and Navarro, C. (2010) HIV Infection Associated with Scleroderma: Report of Two New Cases. Journal of Clinical Pathology, 63, 852-853. https://doi.org/10.1136/jcp.2010.080044

[8] Zandmann-Goddard, G. and Shoenfeld, Y. (2002) HIV and Autoimmunity. Autoimmunity Reviews, 1, 329-337. https://doi.org/10.1016/S1568-9972(02)00086-1

[9] Diallo, S., Mbengue, M., Diallo, R., Diaw, C.A.B., Niasse, M. and Diouf, C. (2016) Maladies systémiques et infections virales: Étude de 95 observations. Communications orales. Revue du Rhumatisme, 83S, A81-A162.

https://doi.org/10.1016/S1169-8330(16)30336-2 